Aarhus School of Architecture // Design School Kolding // Royal Danish Academy

\title{
Communities of everyday practice and situated elderliness as an approach to co- design for senior interaction
}

Brandt, Eva; Binder, Thomas; Malmborg, Lone; Sokoler, Tomas

Published in:

OZCHI 2010 Proceedings

Publication date:

2010

Document Version:

Publisher's PDF, also known as Version of record

Link to publication

Citation for pulished version (APA):

Brandt, E., Binder, T., Malmborg, L., \& Sokoler, T. (2010). Communities of everyday practice and situated elderliness as an approach to co-design for senior interaction. In OZCHI 2010 Proceedings (pp. 400-403).

- Users may download and print one copy of any publication from the public portal for the purpose of private study or research.

- You may freely distribute the URL identifying the publication in the public portal ?

Take down policy

If you believe that this document breaches copyright please contact us providing details, and we will remove access to the work immediately and investigate your claim. 


\section{Communities of everyday practice and situated elderliness as an approach to co-design for senior interaction}

\author{
Eva Brandt, Thomas Binder \\ The Danish Design School \\ Strandboulevarden 47 \\ DK-2100 Copenhagen $\varnothing$, Denmark \\ [ebr, tbi]@dkds.dk
}

\author{
Lone Malmborg, Tomas Sokoler \\ IT University of Copenhagen \\ Rued Langgaards Vej 7 \\ DK-2300 Copenhagen S, Denmark \\ [malmborg, sokoler]@itu.dk
}

\begin{abstract}
In the co-design project Senior Interaction a public care unit, university researchers, industrial partners, and senior citizens are working together to design living labs applying digital concepts that can strengthen social networks and interaction among seniors. When approaching people who we envisioned to be the future users we realized that almost nobody among the people between 55 and 75 years old identified themselves as 'elderly' or 'senior citizens', we realized that users are never just 'out there'. Instead they tend to refer to 'the others' or even to their own parents. Rather than using biological age, institutional categories or similar formal ways to group the people that we imagine as the future users, we suggest to talk about situated elderliness. By associating elderliness not to all encompassing life circumstances but to certain everyday contexts we can turn our attention towards what we call communities of everyday practice that defines these contexts.
\end{abstract}

\section{Author Keywords}

Co-design, design laboratory, recruiting participants, situated elderliness, communities of everyday practices.

\section{ACM Classification Keywords}

User-centered design, theory and methods, prototyping, user issues, miscellaneous.

\section{INTRODUCTION}

This paper reflects on issues relating to recruiting and engaging senior people as users in a co-design project. In the Senior Interaction project a public care unit, two universities, nine private companies and senior citizens collaborate to design concepts that can strengthen social interaction among seniors in a specific urban environment. The overall objective is to develop and explore welfare technologies and service models that support experiences and social interaction among seniors and thus contributing to greater self-reliance and social wellbeing.

OZCHI 2010, November 22-26, 2010, Brisbane, Australia. Copyright the author(s) and CHISIG

Additional copies are available at the ACM Digital Library (http://portal.acm.org/dl.cfm) or ordered from the CHISIG secretary (secretary@chisig.org)

OZCHI 2010 Proceedings ISBN: 978-1-4503-0502-0

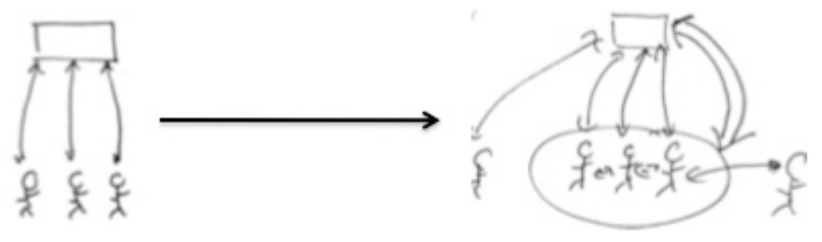

Figure 1: Towards service models supporting social interaction.

The project suggests a move away from service models focusing on a relation between the individual citizen and the service provider towards concepts based on a broader content and social perspective offering opportunities for peer-to-peer communication closely connected to ongoing everyday activities. Focus is on initiating and maintaining locally based networks by offering services to groups of seniors for instance in relation to the meal, exercise and mobility, and cultural experiences. These areas seems to have a great potential of binding people together in a neighborhood and thus contribute to the feeling of belonging and being confident in the local environment.

\section{A LONG TERM DESIGN LABORATORIUM}

The Senior Interaction project uses the design laboratory as a methodological platform for organizing and guiding innovation. With design laboratory we refer to open collaborations between many stakeholders sharing a mutual interest in design research in a particular field. The open collaborations means that "what" is to be designed is not predefined in the outset but something, which is co-designed by the participants, experimented with and rehearsed as the process goes along. The authorship of the results is therefore also shared among the participants (Binder and Brandt, 2008). The design laboratory sets up a learning organization which right from the start simultaneously explore both the "what" to design and "how" to innovate. Thus the approach is different from more traditional approaches that separate research, ideation and concept development from design and implementation (Binder, 2010). The core activities in the design laboratory is series of co-design events where all stakeholders participate in activities that focus on mutual experimentation and learning. Each event usually lasts a half to a full day and is organized to produce 
tangible outputs. In order to succeed it is important to find out who to recruit as participants in the design laboratory and how to organize activities so they create engagement, shared experiences, new knowledge and are found relevant for all parties involved (Brandt and Eriksen, 2010).

The Senior Interaction project began in the late 2009 and is running for three years. It is set up as a long-term design laboratory divided into the following three phases: In a first phase (which forms the basis for this paper) seniors are recruited to the project and invited to take part in a series of three workshops. The first round of workshops is ended by a number of possible use scenarios for communication technologies that provides a possible infrastructure for an enhanced community building. In the second phase the scenarios forms the basis for prototyping in the senior participants everyday environments. The last phase include living labs where seniors in their own homes and local environment try out new service models and welfare technologies.

\section{RECRUITING 'USERS' FOR THE DESIGN LAB}

In co-design processes designers and future users are carrying out central part of the design activities together. As designers we (and/or our possible client) may have an initial idea of who these future users are, but users are never just 'out there'. People have to be recruited and mobilized to enact the roles of future users and to take on the membership in the 'group of users' that the design project enables.

If a design project is well defined and already promoted by strong stakeholders co-design approaches may address the participation of those affected but otherwise not included in the design activity. This was the case in early participatory approaches to systems design, where for example office workers were enrolled in designing new administrative systems (see e.g. Greenbaum and Kyng, 1991). Even though the term user was here also often contested, as it tends to assume that a particular role for those participating is already in place, there was also a powerful rhetorical claim in asking for user participation. As co-design approaches gain ground and become not only a complement to but also the defining methodology for design projects, the definition of relevant participants becomes in itself a controversial issue that must be negotiated in the co-design process.

As the Senior Interaction project was initially negotiated with the institutional partners we decided to apply a broad and loose definition of the group of seniors that should be recruited to the project. We found it important to include seniors who were not in any way in touch with public or private services to the elderly as well as seniors with both little and extensive contact with these services. In terms of age this definition was tentatively translated into 55+. The point in attempting to recruit so broadly was both to ensure to have participants who could take on the long term perspective of the project to innovatively re-think services and infrastructure addressing a strengthening of senior networks around everyday activities, and just as important to establish a realistic life time perspective on senior culture that inevitably include different degrees of dependency on external services. As the Copenhagen Municipality was the lead partner of the project we further decided to recruit seniors from a particular part of the city both to ensure that the professional staff from the municipality could be properly briefed and included in the project activities and to prepare the ground for subsequent living lab activities to be rooted in already existing local networks.

Very soon as we moved on to establish contacts with possible participants the initial definition of seniors proved to be highly controversial. When applying a codesign approach addressing senior citizens this creates a number of issues related to identity, self-image and stigmatization when these senior citizens are to consider themselves potential co-designers. Britt Östlund also addresses this issue of stereotyping elderly and their ability to handle new technologies (Östlund 2005). When do people consider themselves 'elderly', 'old', as 'senior citizens' or similar labels used to categorize people in the late part of their life? And what do identification with such labels entail? When approaching people in the specific urban environment who we envisioned to be the future users we realized that almost nobody among the group of people between 55 and 75 years old identified themselves as 'elderly' or 'senior citizens'. Rather they tend to refer to 'the others' or even to their own parents.

This was particularly striking in an early conversation with a potential participant, whom we had been pointed to because of her active involvement with local community work among seniors. She is herself 75 years old, retired from work and so severely drabbed by arthritis that special arrangements had to be made for setting up the conversation. We had a lively dialogue addressing the vivid activities of the social clubs that our informant was part of organizing, about her personal interest in traveling and of her general discomfort with researchers and research students that want to do studies of little interest to her and her peers. As the conversation moved on to one of the core concepts of our project: communication technology that can grow in importance as the person using it is growing older, a remarkable shift occurred. Our informant now spoke passionately about her recently deceased mother, and how important it had been to her to have well known people around her, while she lived in a local elderly home. Surprisingly it was not immediately attractive for our informant to consider herself a possible user of the technologies that we were envisioning. These experiences are in line with Riche and Mackay who write 'that recruiting proved more difficult than anticipated, in part because people do not appreciate being stigmatized as 'elderly' and because they did not see a direct benefit for themselves" (Riche and Mackay, 2010, p. 78).

The interview above and other early interviews made us realize that we need to find new ways of not only inviting participants into our project, but also to reconsider the way we think of, address and refer to them as future users of the technologies that we are going to co-design. 


\section{COMMUNITIES OF PRACTICE}

Instead of focusing on recruiting individuals for the project an alternative approach might be to use everyday practices as frame and starting point. The concept of communities of practice was originally developed in field of work to capture the skills and competencies enacted by people engaged in a professional practice (Jönsson et al. 2005). Lave and Wenger coined the concept of communities of practice (Lave and Wenger 1991). They write:

"In using the term community, we do not imply some primordial culture-sharing entity. We assume that members have different interests, make diverse contributions to activity, and hold varied viewpoints. In our view, participation at multiple levels is entailed in membership in a community of practice. Nor does the term community imply necessarily co-presence, a welldefined, identifiable group, or socially visible boundaries. It does imply participation in an activity system about which participants share understandings what they are doing and what that means in their lives and for their communities" (ibid. p. 97-98).

Originally the notion of communities of practice was used in the understanding of situated learning processes in organizations, but it has also become quite influential in participatory design as a way of understanding relations between different groups of users in a specific context (Wenger 1998). According to Lesser and Storck, a community of practice is "a group whose members regularly engage in sharing and learning, based on their common interests. One might think of a community of practice as a group of people playing in a field defined by the domain of skills and techniques over which the members of the group interact. Being in the field provides members with a sense of identity - both in the individual sense and in a contextual sense, that is, how the individual relates to the community as a whole" (Lesser and Storck 2001).

When expanding this concept to include everyday practices outside work one could talk about communities of everyday practice, where senior citizens similarly are skillfully enacting everyday practices as seniors. Gradually as they get older they enact what we would call situated elderliness. With situated elderliness we refer to practices that include activities that for some reason or another has become more challenging or perhaps even impossible to carry out by himself or herself. An example could be not being able to pull up one's socks or stockings. Another example is when a bank decides that all transactions have to be carried out over the Internet. A consequence of changing the bank's practices suddenly creates a large group of senior people considered old as they are not able to handle their bank transactions themselves due to lack of experience using the Internet. In these situations in a contextual sense they practice situated elderliness, but simultaneously they might be able to handle all other situations in their everyday life.

\section{Inviting communities of everyday practice}

In relation to recruiting senior people for the Senior Interaction project we visited social clubs, elderly homes and community centres in the local environment. To these initial meetings we brought so-called workbooks containing evocative collages of pictures and text on the themes of the project as a way to both inform them about the project and invite the participants tell stories about their everyday practices and by this hopefully making them interested in participating in the workshops.

The meetings were all lively and the seniors were eager to contribute stories about themselves and particularly the everyday they have together at the club or center. More than 20 seniors accepted the invitation to the first workshop, but though there was a positive interest in the themes of the project, the dialogue at the meetings had a pronounced emphasis on the participants' accounting for who they were and why they were there. When we brought up the issue of building on local networks, the people we talked to came up with stories about how they were actually not from here, as they had either just recently moved to the neighborhood, or had come to the club from an other part of town. When we presented our interpretation of senior life as marked by changes that includes often difficult losses of beloved friends and relatives, we got stories about how mourning and complaining were really not part of what you could share when together with others. When we touched on the possibility to create extended networks between those serviced by the municipal home care service, we got stories about how home care service was really not part of what they felt were needed in their life, and as one man in the meeting came to admit that he had help from home care, the others acknowledged that this was off course different for him as he was a man.

These reactions may seem as contradictions to what we brought to the meetings, and in many ways they are, but as we interpret what we heard, we find that the reactions are as much about not being "boxed in" as "elderly" as they are about rejecting the relevance of the themes that we brought up in the meetings. An observation was also that when meeting with the seniors in for instance a community center they tended first and foremost to provide stories about what they did at the centre. In our co-design process we therefore consider these communities of everyday practice our potential future users and the participants of these communities our collaborating co-designers.

\section{Creating landscapes of everyday communities}

During the second workshop the first activity were to have all the senior participants create a landscape of the various everyday communities of practice that they were part of. Clip-ark with images and stylized silhouettes of human beings were provided to cut from, arrange and glue to the cardboard. There were also a number of flags with text that could be used to name the various communities if they wished to do that. Examples of the text on the flags were: 'Communities across age', 'Help each other in the local environment', 'Fun playing games and having competitions', 'Something 'steady' to meet 
around'. The themes on the flags were based on the stories from the initial meetings and the first workshop. An example of the resulting landscape can be seen in figure 2 .

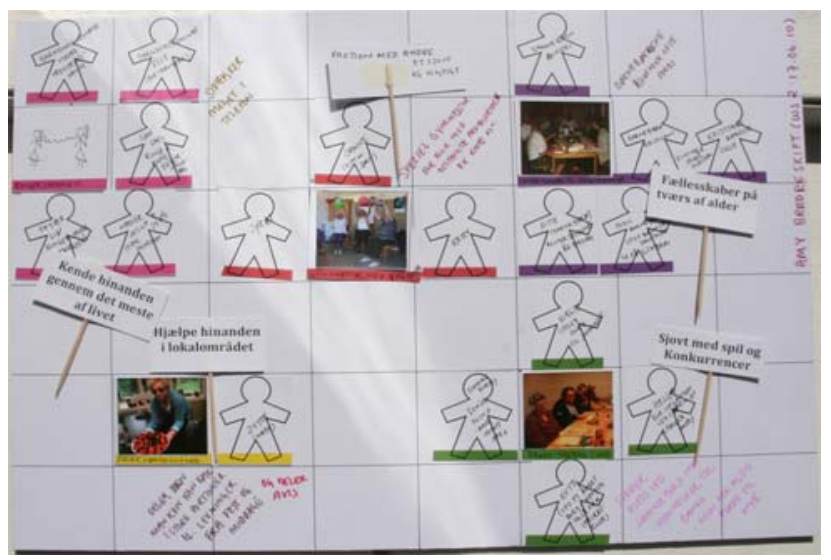

Figure 2: Collage with a landscape of different communities of everyday practices.

When looking at the resulting landscape collages they are of course different as they represent various senior people. Some had for instance very many communities of practices that they were part of others had fewer. Still there seem to be the tendency that each community of practice was distinct in the sense that the people in the various communities did not mix very often. There were for instance the other seniors that they exercised with, another group that they played bingo with, being with the family was another community of practice etc. What seemed to establish the various communities of practices were the activities that were shared. They also seemed most confident in describing the community of practice related to other participants in the workshop. It was easiest to talk about the everyday contexts that were shared within the context of the center. For their part less focus was on for example their children and grandchildren. This might be the seniors way of interpreting what 'we were after' and perhaps negotiating their roles as potential future users.

\section{DISCUSSION}

When the Senior Interaction co-project started we did not know that recruiting seniors already in the initial steps should prove to be so complicated. Our project wants to expose a vivid senior culture spanning the 55 year old just getting to the point of considering that she is in the second part of life and the 93 year old at an elderly care home realizing that life is coming to an end. We may have started out naively assuming that our co-designers are already there ready to embark on our project journey. But constructing who are to be considered as future users is part of the effort. During the initial visits to social clubs, elderly homes and community centers "We are not.." seem to be much more the statements than "yes we are..". Our project seems to depend on a particular definition of being a senior that were much too simplified and stereotype. Rather than using biological age, institutional categories or similar formal ways to group the users that we imagine as the future users, we suggest therefore to talk about situated elderliness. We acknowledge that the rationale of our project is to address and assist citizens in coping with the particular circumstances of for example reduced mobility and potential social isolation associated with becoming elderly. By associating such elderliness not to all encompassing life circumstances but to certain everyday contexts we can turn our attention towards the communities of practice that defines these contexts. When reflecting on our process of recruiting and engaging senior participants as potential users in the project it seems that what we actually did was inviting groups of people sharing some kind of everyday practices to the workshops.

\section{ACKNOWLEDGEMENTS}

Thanks to all the senior participants from the Senior Interaction project for their contribution to this research.

\section{REFERENCES}

Binder, Thomas and Brandt, Eva (2008). The Design:Lab as platform in participatory design research. CoDesign, 4:2, 115-129.

Binder, Thomas (2010). Beyond Methods. In Halse J, Brandt E, Clark B and Binder T (editors). Rehearsing the Future. The Danish Design School Press. 2010.

Brandt and Eriksen (2010). Co-Design Events. In Halse J, Brandt E, Clark B and Binder T (editors). Rehearsing the Future. The Danish Design School Press. 2010.

Greenbaum J. and Kyng M. (edited by) (1991). Design at Work: Corporate Design of Computer Systems. Lawrence Erlbaum Associates, Inc., Publishers.

Jönsson, B., A. Svensk, L. Malmborg et al. (2005). Situated Research and Design for Everyday Life. In: T. Binder and R. Maze (eds.) Proceedings of the NORDES Conference 2005. pp. 1-11. Available at: www.tii.se/reform/inthemaking/files/p1.pdf

Lave, J. and Wenger, E. Situated Learning: Legitimate Peripheral Participation. Cambridge University Press, NY, USA (1991).

Lesser, E. L. and Storck, J. Communities of Practice and Organizational Performance. IBM Systems Journal, Vol. 40, No. 4 (2001). Available online: http://www.research.ibm.com/journal/sj/404/lesser.html (Feb. 2005).

Riche, Yann and Mackay, Wendy (2010). PeerCare: Supporting Awareness of Rhythms and Routines for Better Aging in Place. Computer Supported Cooperative Work (2010) 19:73 - 104. DOI 10.1007/s10606-0099105-z. Springer 2009.

Wenger, E. (1998). Communities of Practice: Learning, Meaning and Identity. Cambridge University Press, NY, USA (1998).

Östlund, B. (2005). Design Paradigms and Misunderstood Technology: The Case of Older Users. In Jæger, B. (ed.) Young Technologies in Old Hands. DJØF pp. 25-39. 